\section{Social Cognition in Older Adults: A Review of Neuropsychology, Neurobiology, and Functional Connectivity}

\section{Abstract}

Title: Social Cognition in Older Adults: A Review of Neuropsychology, Neurobiology, and Functional Connectivity.

Background: Social cognition is an understudied area in cognitive aging. A Medline search using the term "social cognition" and limited to "Aged:65+ years" resulted in only 20 English language references.

Methods and Findings: From these references, and review of additional citations from their reference lists, it appears that older adult's ability to correctly identify another person's state of mind is reduced, but their ability to perceive emotion remains more intact. These deficits may correlate with established areas of agerelated cortical and white matter volume loss in the prefrontal cortex and temporal insula, respectively. Additionally, changes in cerebral functional connectivity with age may contribute to these observations.

Conclusions: This review briefly outlines the neuropsychological, neuroanatomical and functional connectivity literature regarding social cognition in normal cognitive aging. Additionally, we discuss the potential functional implications of age-related changes in social cognition.

\section{Marissa C Natelson Love', Gabrielle Ruff² and David S Geldmacher ${ }^{3}$}

\author{
University of Alabama at Birmingham, \\ 1720 7th Avenue South, Birmingham, AL \\ 35294, USA \\ 2 The OSU Wexner Medical Center, 2050 \\ Kenny Road, Ste. 2335, Columbus, $\mathrm{OH}$ \\ 43221, USA \\ 3 Evelyn F. McKnight Brain Institute, \\ University of Alabama at Birmingham, \\ 1720 7th Avenue South, Birmingham, AL \\ 35294, USA
}

Corresponding author:

Marissa C. Natelson Love

University of Alabama at Birmingham, 1720 7th Avenue South, Birmingham, AL 35294, USA.

\section{$\equiv$ mnatelson@uabmc.edu; ruff.47@buckeyemail.osu.edu; dgeldmacher@uab.edu}

Tel: 205-934-3411

Received: Aug 11, 2015; Accepted: Oct 26, 2015; Published: Oct 28, 2015

\section{Introduction}

Social cognition is the complex interaction of perceiving social cues, processing of those cues within a context and acting accordingly. It has been called a "critical predictor of social competency" [1]. Simply put, it is how humans detect what others are feeling or thinking and respond appropriately. It has been studied most extensively in those diseases where individuals have been the most devastated by its deficits- autism, schizophrenia, and behavioral variant frontotemporal degeneration. Despite, clear and long recognized evidence for changes in social aspects of cognition in aging [2,3], the April 2015 Institute of Medicine (IOM) report titled "Cognitive Aging: Progress in Understanding and Opportunities for Action" [4] does not address this topic. Because of their potential impact on daily function, well-being, and family quality of life, we feel it is important to review differences in social cognition between older and younger adults, and consider them as relevant as other measures to (in the words of the IOM report) "a society that values and sustains cognitive health." (p.352).

\section{Methods}

A Medline search was conducted for the term "social cognition" in any field, and limited to the age group "Aged: 65+ years" and English as the language. This search strategy identified only 20 references (Table 1). Of these, only eleven compared young and old participants on tasks of social cognition, and there was little overlap in methods or terminology. This dearth of systematic research in social cognition in older adults highlights the lack of a widely-accepted definition of what mental properties and skills are included in the definition of social cognition and the most valid methods to test them $[5,6]$. Therefore, even in those diseases in which social cognition has been more thoroughly addressed, the literature is fractured into discussing many narrow aspects of the phenomenology, often tied to a single experimental paradigm [7-12]. Fortunately, there is emerging consensus on conceptual models of social cognition. A panel of experts in schizophrenia proposed consideration of four domains of social cognition: 1) emotion processing, 2) social perception, 3) theory of mind/ mental state attribution, and 4) attributional style/bias [13]. 
Table 1 Results of PubMed search ("Social Cognition" with limits set to "English Language" and "Aged 65+years").

\begin{tabular}{|c|c|c|}
\hline Author(s) & Year & Comments \\
\hline Cosentino, et al. & 2014 & Alzheimer's disease; no healthy older controls \\
\hline Mitchell, et al. & 2014 & Young-old comparison; sensory loss contributes to failures of prosody in aging \\
\hline Slessor, et al. & 2014 & Young-old comparison; own-age bias in social cognition \\
\hline Barber, et al. & 2013 & Older adults only; stereotype threat affects cognitive performance \\
\hline Sambataro, et al. & 2012 & $\begin{array}{l}\text { Young-old comparison; functional connectivity for networks involved in memory (and social cognition) differs } \\
\text { from young to old }\end{array}$ \\
\hline Rakoczy, et al. & 2012 & $\begin{array}{l}\text { Young-old comparison; slowed processing and reduced executive function in aging influences ToM and emotional } \\
\text { recognition }\end{array}$ \\
\hline Kemp, et al. & 2012 & Disease focus (neurodegeneration); review paper \\
\hline Bernstein, et al. & 2011 & Young-old comparison; increased false belief bias with aging on ToM tasks \\
\hline Happe & 2012 & Disease focus (autism) \\
\hline Narvid, et al. & 2009 & Disease focus (fronto-temporal dementia), case study \\
\hline Krendl, et al. & 2009 & Young-old comparison; fMRI study; identified differences in neural response to stigmatized individuals \\
\hline Herndon & 2010 & Conceptual review/hypothesis \\
\hline Sollberger & 2009 & $\begin{array}{c}\text { Disease focus (Neurodegeneration); differences in regional atrophy are associated with personality } \\
\text { characteristics }\end{array}$ \\
\hline Cornelis, et al. & 2009 & Cross-sectional database study; socio-cultural conservatism varies by age more than national political systems \\
\hline Renner, et al. & 2007 & $\begin{array}{l}\text { Young-old comparison; cohort study; personality characteristics are an age-related determinant of physical } \\
\text { exercise }\end{array}$ \\
\hline Keightley, et al. & 2006 & $\begin{array}{l}\text { Young-old comparison; positivity bias in emotional recognition with age; social cognition is a unique domain of } \\
\text { cognition }\end{array}$ \\
\hline Ostir, et al. & 2005 & Disease focus (stroke); social cognition is a predictor of recovery and satisfaction after stroke at age $>40$ \\
\hline Washburn, et al. & 2003 & $\begin{array}{l}\text { Older adults only; relationships between social cognition and general cognition in frail NH residents- social } \\
\text { cognition is a unique domain }\end{array}$ \\
\hline Hess, et al. & 1994 & Young-old comparison; age differences in what information is used to form/change interpersonal impressions \\
\hline Dolen, et al. & 1982 & $\begin{array}{l}\text { Older adults only; social cognition and interaction are related; low interaction more strongly predicts general } \\
\text { cognitive decline }\end{array}$ \\
\hline
\end{tabular}

Unfortunately, not all of these aspects of social cognition have been well-studied in "normal cognitive aging". Heberlein and Adolphs [14] conceptualized social cognition along two main dimensions, perception and attribution. These align closely with Pinkham [13] and colleagues' "emotion processing" and "theory of mind/mental state attribution" categories [13]. The latter is also conceptually related to the phenomenon of "mentalizing" used by some authors.

\section{Observed age effects in social cognition}

By far, theory of mind (ToM) is the best studied of Pinkham [13] and colleagues' four domains of social cognition in aging. Its development in childhood requires skills in executive function, especially conflict inhibition [15]. It has been described as having both cognitive ("cold") and affective ("hot") domains. Cognitive ToM is defined as the ability to predict what another person is thinking while affective ToM is the ability to predict what they are feeling. Affective ToM differs from empathy in that it is the knowledge of another's feeling rather than experiencing it yourself [16]. It can be referred to as "cognitive empathy". Cognitive ToM is frequently tested with a "false-belief" task- a task where someone is asked to identify someone else's belief despite having knowledge that reality conflicts with that belief. This can be measured in a first-order task ("he thinks that ...") or with a more complex second-order tasks ("he thinks that she thinks that..."). Older individuals tend to perform equally to their younger counterparts on a first-order "false-belief" task but worse on a second-order test of cognitive ToM [17-19]. Affective ToM is impaired in normal cognitive aging, despite intact basic facial emotion recognition $[15,16,18]$. This is frequently tested by "The Eyes" task where the person is asked to pick a word to describe how a person is feeling based on seeing only their eyes [20].

In contrast, the existing literature on the other domains of social cognition is much more limited. Studies of emotion processing suggest that older adults experience a bias towards positivity in interpretation of facial emotions with aging [21-25]. One study suggested that social perception appears preserved in aging [26] while another suggested it might appear so as compensation for other age-related cognitive deficits [27].

\section{Methodological issues}

Unfortunately, the methodologies of studies of social cognition are fraught with the same kinds of challenges faced by studies of more discrete cognitive functions like memory or language [28]. Of the 20 citations identified by our primary literature search, no two used the same experimental paradigm. There are inherent difficulties in studying "normal aging" in that there is a selection bias to those that are enrolled as participants. The really successfully aging individuals may not participate in research because they are too busy while, on the other end of the spectrum, there are also those that are too ill [29]. People with low functional status or limited social and financial support may be less likely to enroll in studies [30]. Additionally, due to 
the demands of neuropsychological testing, those with primary languages other than English and those below a certain education level are often excluded from study. Most studies rely on a cross-sectional design, comparing subjects from different age groups. However, there is an inherent confound to that design because of generational differences. The life experiences are very different and may make the group demographics dissimilar. What is required socially and educationally for one generation is very different than that required for another generation. In social cognition, generational differences must be specifically considered, as social norms vary across age cohorts independently of the age of the subjects. Cohort differences may overestimate the effects of aging [31].

Although longitudinal studies are likely a better model, they present logistical changes and their own biases. Populations undergo attrition, leaving the healthiest, most educated and wealthiest-and perhaps the most socially adept-participants to represent the original study group [32]. Also, repeating the same measures over time allows for a practice effect which may buoy someone's scores despite cognitive decline over time [33,34]. The insidious onset of cognitive decline in dementia syndromes may result in including some subjects as "cognitively normal" who are in fact experiencing preclinical or mild symptomatic expressions of disease.

Additionally, the experimental paradigms may not represent the complex environment in which someone lives and which influences spontaneous and social behaviors. Tests that measure neuropsychological skills are often used as comparisons for more socially determined cognitive tasks. Neuropsychological and cognitive test stimuli can be classified to specific domains including verbal, visual-static, visual-dynamic, verbal and visualstatic, and verbal and visual-dynamic [1]. Reality typically involves stimuli that are dynamic and include verbal and visual information. Older individuals may have greater crystallized intelligence (vocabulary and general knowledge) that lends an advantage in verbal tasks $[18,35]$. The tests also use unfamiliar terms because people tend not to give verbal labels to the underlying steps of emotion processing. Without the language to describe it, it is difficult to parse out the functions involved between perception and behavior [18]. Thus, age-related changes in other areas of cognition may also influence the interpretation of social cognition tasks. And last but not least, there is some heritability of social cognition, much like personality, that is difficult to study in vivo due to the complexity of the environment of development [3638].

\section{Neuropsychology of social cognition and aging}

The majority of studies in this area have focused on mental state attribution (ToM) or explicit emotion recognition. Of course, there is a need to better understand what perceptual features and cognitive tasks are needed in order to achieve social cognition (Figure 1). Social behaviors are the outcome of both external and internal events. Stimuli in the environment are processed both for primary sensory characteristics and for attribution of their social significance. The behaviors result when both the external stimuli and drive states are sufficiently motivating to generate a response in the environment. Subjectively, informants describe changes in personality and interpersonal conduct with aging. There may be a loss of empathy, increased stereotyped behaviors, disinhibition and emotion dysregulation [1]. However, older adults tend to lack the metacognition required to predict their own decline [16].

Methodologic issues plague research in this area similar to the other areas of cognitive aging. Coexisting cognitive deficits must be controlled for when trying to isolate social cognition deficits. Many of these tasks create demand on executive function abilities including: reasoning with unfamiliar material, conflict inhibition and mental flexibility, all of which have been shown to decline with age. For example, older adults attend less to the eye region of faces than their younger counterparts [18]. Studies should be designed to include controls for more elementary perceptual and cognitive deficits likes prosopagnosia in a facial emotion recognition task. Interestingly, basic emotions (those that are cross-culturally recognized e.g., happiness, sadness, fear) appear to be better preserved than more complex ones in aging. This may be explained by the decreased ability to evaluate the social context and apply reasoning [16].

Additionally, testing methods must be ecologically valid. Although it is less time-consuming to show someone a series of static pictures or a verbal passage, a video of a social interaction may be more likely to predict performance outside of the testing arena. In static images or verbal passages, subjects cannot recreate "bodily cues". These cues are also difficult to measure due to their subtlety. However, in one study of nursing home residents, nurse's ratings of resident's social behavior correlated well with deficits on social cognition testing [39]. In a metaanalysis [18] that divided ToM tasks into domains (cognitive, affective or mixed) and modalities (verbal, visual-static, visualdynamic, verbal and visual-static, and verbal and visual-dynamic), they evaluated how well the studies controlled for some of these methodologic concerns. When accounting for the advantage of the older adults' crystallized intelligence on verbal tasks, declines were more apparent. In fact, there were deficits across all domains and modalities when control tasks were used. These results were replicated in participants aged $50-90$ years old while controlling for verbal intelligence, executive functioning and processing speed in a diffusion tensor imaging study that showed declining ToM associated with white matter volume loss [17].

In the tests measuring ToM, some find that affective and cognitive ToM abilities are dissociable while others find that deficits in both coexist. When controlling for the fluid intelligence deficits of normal aging, the results of studies are mixed on the significance of changes in social cognition. So, that leaves us with the question of whether ToM (and social cognition) is a problem with performance due to executive function deficits or if it is a distinct entity in which we lose competence as we age [15]. We have come to expect some cognitive functions to decline with age while some do not, because they share localization with social cognition. We should expect that, similarly, some parts of social cognition decline and some do not. (Table 2)

\section{Neuroanatomy of aging and social cognition}

Most neuropsychological observations originate from testing 
Table 2 Localization and age related change in cognitive processes.

\begin{tabular}{|c|c|c|}
\hline Cognitive Process & Primary Cortical Localization & Observed Changes with Aging \\
\hline Processing Speed & Prefrontal & Decline \\
\hline Attention & Prefrontal & $\begin{array}{l}\text { Simple - no change } \\
\text { Divided - decline } \\
\text { Selective - decline }\end{array}$ \\
\hline Memory & $\begin{array}{c}\text { Temporal Cortex } \\
\text { Archicortex (hippocampus) }\end{array}$ & $\begin{array}{l}\text { Implicit - no change } \\
\text { Episodic - decline } \\
\text { Semantic - decline (late) }\end{array}$ \\
\hline Executive function & Prefrontal & Decline \\
\hline \multicolumn{3}{|l|}{ Social Cognition } \\
\hline - Emotional Perception & Temporal Insula & Minimal Change \\
\hline - Attribution & Prefrontal & Decline \\
\hline
\end{tabular}

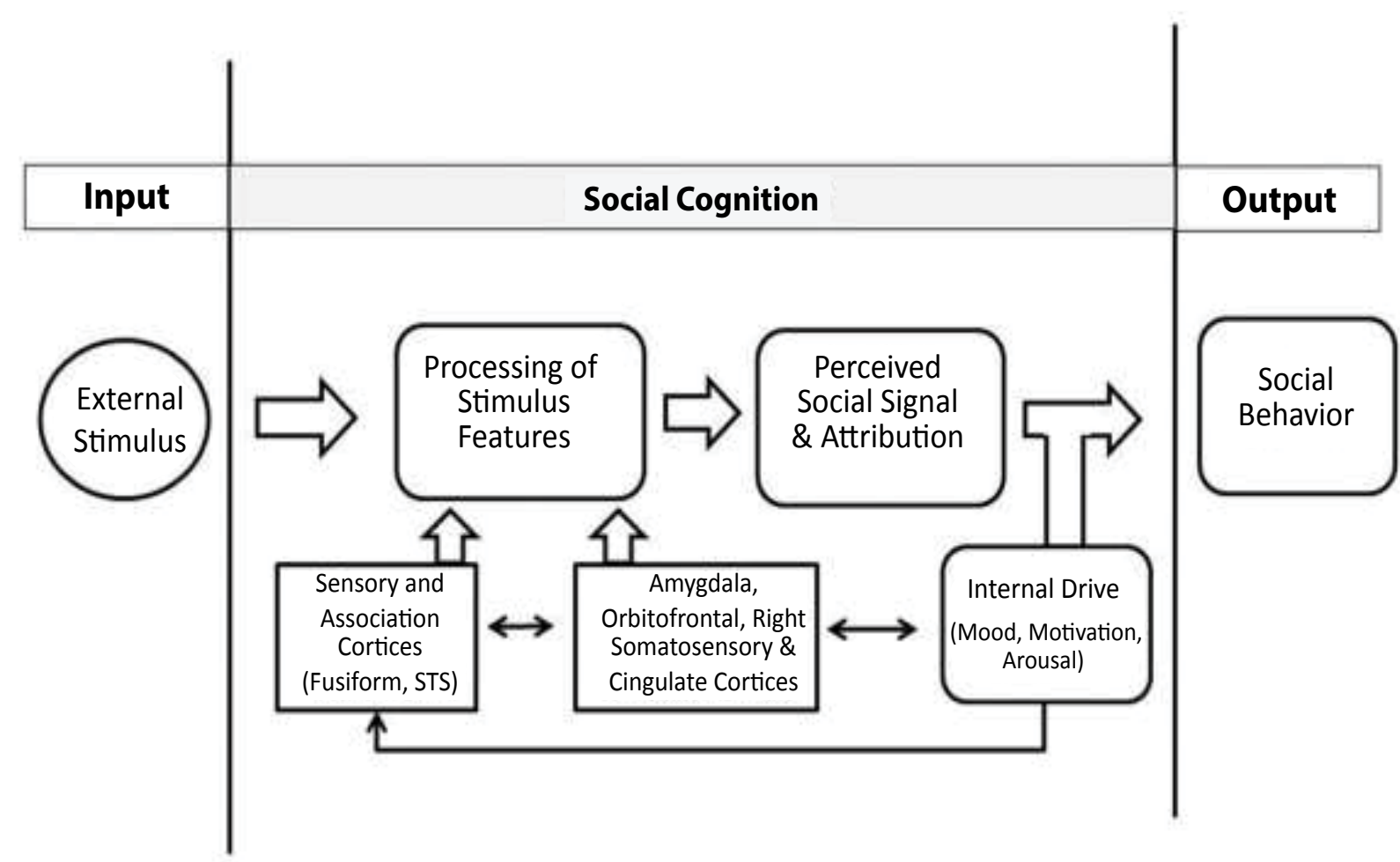

Figure 1 Elements of social cognition. Social behaviors are the outcome of both external and internal events. Stimuli in the environment are processed both for primary sensory characteristics and for attribution of their social significance. The behaviors result when both the external stimuli and drive states are sufficiently motivating to generate a response in the environment.

paradigms designed to assess patterns of cognitive function or loss associated with anatomical lesions. Gray matter volume begins to decrease after age 20 years [40]. The amount of atrophy is most prominent in the prefrontal cortex (Figure 2). Age-related changes in the temporal lobes are more moderate and involve decreases in the volume of the hippocampus [41]. The entorhinal cortex, which serves as a relay center between the hippocampus and association areas, has been reported to undergo early decreases in volume in Alzheimer dementia (AD), but not in normal aging) [42]. Despite the numerous theories explaining neuronal loss, decline in gray matter volume in older adults is best explained not by death of the neurons themselves but by a decrease in their size and the number of connections between them $[40,43]$. This reduction in synaptic density is well documented in older adults, and according to the model created by Terry and Katzman [40], by the age of 130 years a cognitively normal adult will have a synaptic density equivalent to someone with AD. Neurons undergo morphologic changes with aging, including a decrease in the complexity of dendrite arborization, decreased dendrite length, and decreased neuritic spines (the major sites for excitatory synapses). These morphologic changes likely contribute directly to the reduction of synaptic density [44].

Decreases in white matter volume are much greater than those in gray matter with increasing age [45]. In one study using morphometric methods from autopsy data of neurologically normal subjects, there was a $16 \%$ to $20 \%$ decrease in white 


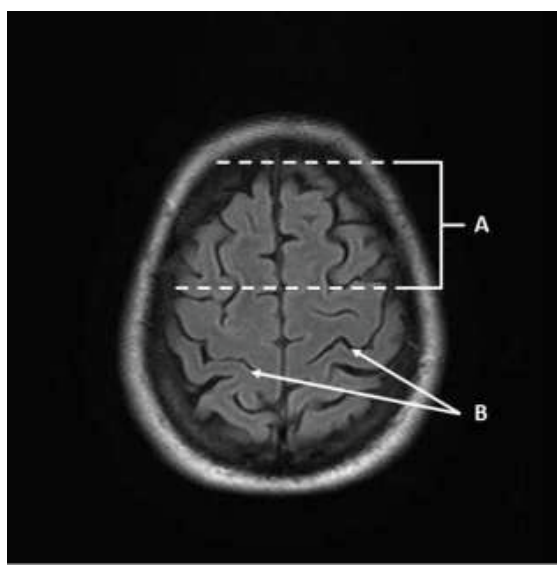

Figure 2 Neuroanatomical changes with aging. Prefrontal cortical volume decreases with age. This region is associated with changes in social cognition, especially attribution of others' states of mind. Prefrontal cortex $(\mathrm{A})$ is identified by mapping the motor and premotor gyri in front of the central sulcus (B) on a brain magnetic resonance image of a 72 year old man with intact social function and normal general cognitive performance (Modified Mini-Mental State exam score 93/100; 41st percentile for age).

matter volume in subjects older than 70 years in comparison with younger subjects. This shrinkage of white matter was noted in the precentral gyrus, gyrus rectus, and corpus callosum, areas that demonstrated less than $6 \%$ declines in gray matter volume [46]. This study was limited by the small sample size. Nonetheless, these findings have been supported by others; for example, Rogalski and colleagues [47] described that parahippocampal white matter was decreased, leading to decreased communication with hippocampal structures and suggesting a possible mechanism for age-associated decline in memory.

In addition to changes in structure of white matter, a decline in the function of white matter has been studied using diffusion tensor imaging (DTI). DTI has allowed the observation in vivo that white matter integrity declines with increasing age. O'Sullivan and colleagues [48] showed age-related declines in white matter tract integrity are most marked in the anterior white matter and are associated with deficits in executive function. Madden and colleagues [49] showed that loss of integrity of the central portion of the corpus callosum may mediate age-related cognitive decline.

Social cognition relies on areas in the temporal and frontal lobes that show volume loss in normal cognitive aging. The anatomy necessary for facial emotion recognition in social cognition includes the fusiform gyrus for its contribution to facial recognition as well as the superior temporal sulcus which recognizes the changeable aspects of faces [50]. The amygdala is required to connect the perception with a behavior and to assign social and emotional value to the stimulus [36]. The amygdala is also critical for detecting negative emotions, especially fear and for assessing the gaze of others. When it is lesioned, individuals become placid and more trusting. Future research might assess whether decreased connections from parahippocampal white matter are sufficient to produce these changes with aging as well [51].

Lesion studies implicate the right somatosensory cortex as a critical contributor to ToM. Other studies have also linked the medial prefrontal cortex to ToM [52]. Lesion studies with the ventromedial frontal cortex showed inability to make a decision based on a hunch (inability to acquire, represent and retrieve values of our actions) or by reading somatic markers. Lesions of the orbitofrontal cortex lead to the inability to plan and execute future plans. Typically, these lesions lead to using stereotyped and inappropriate mannerisms, an apparent lack of concern and diminished capacity to respond to punishment [36]. The prefrontal cortex may also serve to regulate or inhibit other brain regions, like the amygdala, so as to control impulses, aggression and violent behavior. The expected changes in social cognition may be attributed to the volume loss in the prefrontal cortex that is described above in normal aging.

The neurotransmitter systems involved in the changes seen with cognitive aging have been less well-defined than the neuroanatomical changes. Beyond its well-known effects in reward behaviors, the dopaminergic system has been implicated for the decreased processing speed, working memory and cognitive control associated with normal cognitive aging [53]. Serotoninergic systems also decrease with aging and this may play a role in the changes in emotion regulation and recognition [54]. Higher levels of the neuropeptide oxytocin may be beneficial for social perception but its level with aging does not appear to have been studied [55].

\section{Functional connectivity of social cognition}

Important clues to the neurobiological bases of social cognition can be discerned from both animal studies and human imaging work, especially functional connectivity determined by Blood Oxygen Level Dependent (BOLD) functional Magnetic Resonance Imaging (fMRI) studies. Among the domains of social cognition identified by Pinkham and colleagues [13], the clearest evidence for neurobiological substrates exists for emotion processing, and theory of mind/mental state attribution. In the perception vs. attribution model [15], perception is fast, automatic, and not significantly influenced by top-down processes.

A critical step in understanding the perceptual aspects of emotional processing emerged from the discovery of "mirror neurons" in macaque monkeys. These neurons, located principally in the ventral premotor cortex of the frontal lobe, show increased activity when an animal conducts a behavior, but also when it observes a similar action in another animal $[56,57]$. Similarly, both imaging and electrophysiologic studies in humans have identified increased activation of the anterior insula in response to emotional facial expressions of others' especially for disgust [58,59]. Reduced reactivity to expressions of disgust in other people has also been reported for a man who sustained a stroke involving the left insula [60]. Overlapping activation patterns in the insula have subsequently been reported for both the observation and imitation of facial expressions of others [61]. On the basis of these observations, Gallese and colleagues' [62] proposed that mirror neuron systems partially recreate the 
internal state of emotional experience and are normally activated upon observation of another's emotional expressions. These activation patterns are highly consistent with the fast, bottom up processes proposed for emotion perception. However, the effect of aging on these mirror neuron processes remains incompletely explored.

In contrast, numerous studies have demonstrated age-related changes in the functional connectivity of brain regions, including changes in systems associated with emotion processing [63,64]. This has important implications for social cognition along the aging process. Interestingly, some brain regions linked to insular regions with emotional state mirror neurons, such as the anterior cingulate cortex (ACC), show increased activation in older subjects [65]. The rostral ACC, which has been linked to assessing the salience of emotional signals [66] demonstrates stronger connectivity with the insula in older adults. Conversely, dorsal ACC and posterior insula show diminished connectivity with the default mode network. This may provide a partial neurobiological explanation for age-related preservation of social perception and emotion (particularly the positivity bias), as well as the reduced mentalizing ability associated with poorer activation of the DMN.

The attributional aspects of social cognition including Theory of Mind have been associated with activity in different cerebral networks, especially key nodes of the Default Mode Network (DMN), including medial prefrontal cortex, posterior cingulate cortex, temporoparietal junction, and superior temporal sulcus. This network, associated with internally focused states of mind like introspection and retrospection, shows significant reductions in activation and connectivity with aging [67] including reduced connectivity with the rostral ACC [65]. Not surprisingly, older adults were less accurate in tasks that required judging others' beliefs and intents; tasks involving non-social aspects of cognition did not show similar decrements [52]. The dorsomedial frontal cortex was the one brain area showing decreased BOLD activation across all three of Moran and colleagues' [52] social attribution tasks. Other authors have not observed similar decrements in either attributional performance or dorsomedial frontal activation.

\section{Practical implications of changes in social cognition with aging}

Socialization is an integral part of life. The importance of interaction with others does not decrease with age, and is an important correlate of general cognitive health [68]. Washburn and colleagues [39] identified that frail elders were impaired on numerous tasks of social cognition. At a practical level, these impairments were significantly and independently associated with social functioning, even when controlling for executive function and memory tasks. Although many studies have explored methods to improve social cognition, there are currently no standardized recommendations to prevent or reverse declining social cognition.

Intact social cognition is an important aspect of navigating the complexities of daily interpersonal interactions. Whether an individual is running a business, making a purchase, or maintaining a relationship, social cognition plays a crucial role in the outcome of human encounters. It is possible that societal stereotypes, for instance, the "grumpy old man," have their basis in normal trajectories of social cognition across the lifespan. Additionally, well described changes in social cognition, such as the positivity bias [69] and difficulties in determining the intent of others [52] may underlie some of the vulnerability of older adults to financial exploitation.

\section{Summary}

Social cognition is an understudied area in cognitive aging, barely receiving mention in the IOM's 2015 "Progress in Understanding and Opportunities for Action" report. Yet, it may have far reaching implications for the social functioning, cognitive health, and overall well-being of older adults and their families. The effects of social cognitive impairment in disease is clear from illnesses like schizophrenia, in which, "the capacity to appreciate mental states predicts social competence more strongly than neurocognitive function or clinical symptom severity" [13] and similar, if more subtle, abnormalities may emerge as part of the aging process. Losses in the ability to judge another's intent may represent a critical source of vulnerability in our increasingly aged population. Therefore, in accordance with the IOM's recent call for advancements in research and understanding of healthy cognitive aging [4] (p. 351-2), evolving changes in social cognition among older adults further warrants attention.

\section{Acknowledgements}

The authors wish to thank Elizabeth Crooks, DNP, RN, CNE for her comments on the manuscript and assistance with Figure 1. 


\section{References}

1 Henry JD, Cowan DG, Lee T, Sachdev PS (2015) Recent trends in testing social cognition. Current opinion in psychiatry 28: 133-140.

2 Hess TM, Blanchard-Fields F (1999) Social Cognition and Aging.

Hess TM, Pullen SM (1994) Adult age differences in impression change processes. Psychology and aging 9: 237-250.

4 Blazer DG, Yaffe K, Karlawish J (2015) Cognitive Aging: A Report From the Institute of Medicine. Jama.

5 Mitchell RL, Kingston RA (2014) Age-related decline in emotional prosody discrimination: acoustic correlates. Exp Psychol 61: 215-223.

6 Slessor G, Phillips LH, Ruffman T, Bailey PE, Insch P (2014) Exploring own-age biases in deception detection. Cogn Emot 28: 493-506.

7 Cosentino S, Zahodne LB, Brandt J, Blacker D, Albert M, et al. (2014) Social cognition in Alzheimer's disease: a separate construct contributing to dependence. Alzheimer's \& dementia: the journal of the Alzheimer's Association 10: 818-826.

8 Kemp J, Despres O, Sellal F, Dufour A (2012) Theory of Mind in normal ageing and neurodegenerative pathologies. Ageing research reviews 11: 199-219.

9 Happe F, Charlton RA (2012) Aging in autism spectrum disorders: a mini-review. Gerontology 58: 70-78.

10 Narvid J, Gorno-Tempini ML, Slavotinek A, Dearmond SJ; Cha YH, et al. Of brain and bone: the unusual case of Dr. A. Neurocase 15: 190-205.

11 Sollberger M, Stanley CM, Wilson SM, Gyurak A, Beckman V, et al. (2009) Neural basis of interpersonal traits in neurodegenerative diseases. Neuropsychologia 47: 2812-2827.

12 Ostir GV, Smith PM, Smith D, Ottenbacher KJ (2005) Functional status and satisfaction with community participation in persons with stroke following medical rehabilitation. Aging Clin Exp Res 17: 35-41.

13 Pinkham AE, Penn DL, Green MF, Buck B, Healey K, et al. (2014) The social cognition psychometric evaluation study: results of the expert survey and RAND panel. Schizophrenia bulletin 40: 813-823.

14 Heberlein AS, Adolphs R (2005) Functional anatomy of human social cognition. The cognitive neuroscience of social behaviour: Psychology Press, New York, NY; Pp: 157-194.

15 Rakoczy H, Harder-Kasten A, Sturm L (2012) The decline of theory of mind in old age is (partly) mediated by developmental changes in domain-general abilities. British journal of psychology 103: 58-72.

16 Duval C, Piolino P, Bejanin A, Eustache F, Desgranges B (2011) Age effects on different components of theory of mind. Consciousness and cognition 20: 627-642.

17 Charlton RA, Barrick TR, Markus HS, Morris RG (2009) Theory of mind associations with other cognitive functions and brain imaging in normal aging. Psychology and aging 24: 338-348.

18 Henry JD, Phillips LH, Ruffman T, Bailey PE (2013) A meta-analytic review of age differences in theory of mind. Psychology and aging 28: 826-839.

19 Bernstein DM, Thornton WL, Sommerville JA (2011) Theory of mind through the ages: older and middle-aged adults exhibit more errors than do younger adults on a continuous false belief task. Experimental aging research 37: 481-502.

20 Baron-Cohen S, Wheelwright S, Hill J, Raste Y, Plumb I (2001) The "Reading the Mind in the Eyes" Test revised version: a study with normal adults, and adults with Asperger syndrome or highfunctioning autism. J Child Psychol Psychiatry 42: 241-251.

1 Bell R, Giang T, Mund I, Buchner A (2013) Memory for reputational trait information: is social-emotional information processing less flexible in old age? Psychology and aging 28: 984-995.

22 Bucks RS, Garner M, Tarrant L, Bradley BP, Mogg K (2008) Interpretation of emotionally ambiguous faces in older adults. The journals of gerontology Series B, Psychological sciences and social sciences 630: P337-343.

23 Horning SM, Cornwell RE, Davis HP (2012) The recognition of facial expressions: an investigation of the influence of age and cognition. Neuropsychology, development, and cognition Section B, Aging, neuropsychology and cognition 19: 657-676.

24 Johnson DR, Whiting WL (2013) Detecting subtle expressions: older adults demonstrate automatic and controlled positive response bias in emotional perception. Psychology and aging 28: 172-178.

25 Keightley ML, Winocur G, Burianova H, Hongwanishkul D, Grady CL (2006) Age effects on social cognition: faces tell a different story. Psychology and aging 21: 558-572.

26 Freund AM, Isaacowitz DM (2014) Aging and social perception: so far, more similarities than differences. Psychology and aging 29: 451453.

27 Herndon JG (2015) The grandmother effect: implications for studies on aging and cognition. Gerontology 56: 73-79.

28 Barber SJ, Mather M (2013) Stereotype threat can both enhance and impair older adults' memory. Psychological science 24: 2522-2529.

29 Minder CE, Muller T, Gillmann G, Beck JC, Stuck AE (2002) Subgroups of refusers in a disability prevention trial in older adults: baseline and follow-up analysis. American journal of public health 92: 445-450.

30 Ford JG, Howerton MW, Lai GY, Gary TL, Bolen S, et al. (2008) Barriers to recruiting underrepresented populations to cancer clinical trials: a systematic review. Cancer 112: 228-242.

31 Hedden T, Gabrieli JD (2004) Insights into the ageing mind: a view from cognitive neuroscience. Nature reviews Neuroscience 5: 87-96.

32 Van Beijsterveldt CE, van Boxtel MP, Bosma H, Houx PJ, Buntinx F, et al. (2002) Predictors of attrition in a longitudinal cognitive aging study: the Maastricht Aging Study (MAAS). J Clin Epidemiol 55: 216223.

33 Salthouse TA (2010) Influence of age on practice effects in longitudinal neurocognitive change. Neuropsychology 24: 563-572.

34 Abner EL, Dennis BC, Mathews MJ, Mendiondo MS, Caban-Holt A, et al. (2012) Investigators, P.R.; Crowley, J.J.; Investigators, S. Practice effects in a longitudinal, multi-center Alzheimer's disease prevention clinical trial. Trials 13: 217.

35 Salthouse T (2012) Consequences of age-related cognitive declines. Annual review of psychology 63: 201-226.

36 Adolphs R (2001) The neurobiology of social cognition. Current opinion in neurobiology 11: 231-239.

37 Renner B, Spivak Y, Kwon S, Schwarzer R (2007) Does age make a difference? Predicting physical activity of South Koreans. Psychology and aging 22: 482-493.

38 Cornelis I, Van Hiel A, Roets A, Kossowska M (2009) Age differences in conservatism: evidence on the mediating effects of personality and cognitive style. J Pers 77: 51-87. 
39 Washburn AM, Sands LP, Walton PJ (2003) Assessment of socia cognition in frail older adults and its association with socia functioning in the nursing home. The Gerontologist 43: 203-212.

40 Terry RD, Katzman R (2001) Life span and synapses: will there be a primary senile dementia? Neurobiology of aging 22: 347-348.

41 Raz N, Rodrigue KM, Head D, Kennedy KM, Acker JD (2004) Differential aging of the medial temporal lobe: a study of a five-year change. Neurology 62: 433-438.

42 Braak H, Braak E (1996) Evolution of the neuropathology of Alzheimer's disease. Acta neurologica Scandinavica Supplementum 165: 3-12.

43 Resnick SM, Pham DL, Kraut MA, Zonderman AB, Davatzikos C (2003) Longitudinal magnetic resonance imaging studies of older adults: a shrinking brain. The Journal of neuroscience: the official journal of the Society for Neuroscience 23: 3295-3301.

44 Dickstein DL, Kabaso D, Rocher AB, Luebke JI, Wearne SL, et al. (2007) Changes in the structural complexity of the aged brain. Aging cell 6: 275-284.

45 Salat DH, Kaye JA, Janowsky JS (1999) Prefrontal gray and white matter volumes in healthy aging and Alzheimer disease. Archives of neurology 56: 338-344.

46 Meier-Ruge W, Ulrich J, Bruhlmann M, Meier E (1992) Age-related white matter atrophy in the human brain. Annals of the New York Academy of Sciences 673: 260-269.

47 Rogalski E, Stebbins GT, Barnes CA, Murphy CM, Stoub TR, et al. (2012a) Age-related changes in parahippocampal white matter integrity: a diffusion tensor imaging study. Neuropsychologia 50 1759-1765.

48 O'Sullivan M, Summers PE, Jones DK, Jarosz JM, Williams SC, et al. (2001) Normal-appearing white matter in ischemic leukoaraiosis: a diffusion tensor MRI study. Neurology 57: 2307-2310.

49 Madden DJ, Spaniol J, Costello MC, Bucur B, White LE, et al. (2009) Cerebral white matter integrity mediates adult age differences in cognitive performance. Journal of cognitive neuroscience 21: 289-302.

50 Haxby JV, Hoffman EA, Gobbini MI (2000) The distributed human neural system for face perception. Trends in cognitive sciences 4: 223-233.

51 Rogalski E, Stebbins G, Barnes C, Murphy C, Stoub T, et al. (2015b) Age-related changes in parahippocampal white matter integrity: $A$ diffusion tensor imaging study. Neuropsychologia 50: 1759-1765.

52 Moran JM, Jolly E, Mitchell JP (2012) Social-cognitive deficits in normal aging. The Journal of neuroscience: the official journal of the Society for Neuroscience 32: 5553-5561.

53 Backman L, Nyberg L, Lindenberger U, Li SC, Farde L (2006) The correlative triad among aging, dopamine, and cognition: current status and future prospects. Neuroscience and biobehavioral reviews 30: 791-807.

54 Li SC (2013) Neuromodulation and developmental contextual influences on neural and cognitive plasticity across the lifespan. Neuroscience and biobehavioral reviews 37: 2201-2208.
Ebner NC, Maura GM, Macdonald K, Westberg L, Fischer H (2013) Oxytocin and socioemotional aging: Current knowledge and future trends. Frontiers in human neuroscience 7: 487.

56 Gallese V, Fadiga L, Fogassi L, Rizzolatti G (1996) Action recognition in the premotor cortex. Brain: a journal of neurology 119: 593-609.

57 Rizzolatti G, Fadiga L, Gallese V, Fogassi L (1996) Premotor cortex and the recognition of motor actions. Brain research Cognitive brain research 3: 131-141.

58 Phillips ML, Young AW, Senior C, Brammer M, Andrew C, et al. (1997) A specific neural substrate for perceiving facial expressions of disgust. Nature 389:495-498.

59 Krolak-Salmon P, Henaff MA, Vighetto A, Bertrand O, Mauguiere F (2004) Early amygdala reaction to fear spreading in occipital, temporal, and frontal cortex: a depth electrode ERP study in human. Neuron 42: 665-676.

60 Calder AJ, Keane J, Manes F, Antoun N, Young AW (2000) Impaired recognition and experience of disgust following brain injury. Nature neuroscience 3: 1077-1078.

61 Carr L, lacoboni M, Dubeau MC, Mazziotta JC, Lenzi GL (2003) Neural mechanisms of empathy in humans: a relay from neural systems for imitation to limbic areas. Proceedings of the National Academy of Sciences of the United States of America 100: 5497-5502.

62 Gallese V, Keysers C, Rizzolatti GA (2004) Unifying view of the basis of social cognition. Trends in cognitive sciences 8: 396-403.

63 Sambataro F, Safrin M, Lemaitre HS, Steele SU, Das SB, et al. (2012) Normal aging modulates prefrontoparietal networks underlying multiple memory processes. The European journal of neuroscience 36: 3559-3567.

64 Krendl AC, Heatherton TF, Kensinger EA (2009) Aging minds and twisting attitudes: an $\mathrm{fMRI}$ investigation of age differences in inhibiting prejudice. Psychology and aging 24: 530-541.

65 Cao W, Luo C, Zhu B, Zhang D, Dong L, et al. (2014) Resting-state functional connectivity in anterior cingulate cortex in normal aging. Frontiers in aging neuroscience 6:280.

66 Bush G, Luu P, Posner MI (2000) Cognitive and emotional influences in anterior cingulate cortex. Trends in cognitive sciences 4: 215-222.

67 Andrews-Hanna JR, Snyder AZ, Vincent JL, Lustig C, Head D, et al. (2007) Disruption of large-scale brain systems in advanced aging. Neuron 56: 924-935.

68 Dolen LS, Bearison DJ (1982) Social interaction and social cognition in aging. A contextual analysis. Human development 25: 430-442.

69 McDowell CL, Harrison DW, Demaree HA (1994) Is right hemisphere decline in the perception of emotion a function of aging? The International journal of neuroscience 79: 1-11. 